\section{(- OPEN ACCESS}

\title{
Enhancement of PTSD treatment through social support in Idobata-Nagaya community housing after Fukushima's triple disaster
}

\author{
Arinobu Hori, ${ }^{1,2}$ Tomohiro Morita, ${ }^{3}$ Izumi Yoshida, ${ }^{4}$ Masaharu Tsubokura ${ }^{3,5}$
}

${ }^{1}$ Department of Psychiatry, Hori Mental Clinic, Fukushima, Japan ${ }^{2}$ Department of Disaster and Comprehensive Medicine, Fukushima Medical University School of Medicine, Fukushima, Japan

${ }^{3}$ Internal Medicine, Soma Central Hospital, Fukushima, Japan

${ }^{4}$ Semmelweis University, Budapest, Hungary

${ }^{5}$ Department of Public Health, Fukushima Medical University School of Medicine, Fukushima, Japan

Correspondence to Dr Arinobu Hori arinobu.h@gmail.com

Accepted 31 May 2018
Check for updates

To cite: Hori A, Morita T, Yoshida I, et al. BMJ Case Rep Published Online First: [please include Day Month Year]. doi:10.1136/bcr-2018224935

\section{SUMMARY}

Cognitive-behavioural therapy is a first-line treatment for post-traumatic stress disorder (PTSD), but it is difficult to implement in disaster settings. We report the case of an 80-year-old Japanese woman, who was diagnosed with PTSD after the 2011 triple disaster (earthquake, tsunami and nuclear plant accident) in Fukushima. Her recovery was greatly enhanced by the social support she received while living in Idobata-Nagaya community housing, established by Soma city in Fukushima, where residents could naturally discuss their traumatic experiences. Habituation to traumatic memories and processing of cognitive aspects of the psychological trauma, which are therapeutic mechanisms of traumafocused psychotherapies, spontaneously occurred in this setting. The details of this case support the effectiveness of Idobata Nagaya as a provider of psychological first aid, an evidence-informed approach to assist children, adolescents, adults and families in the aftermath of a disaster.

\section{BACKGROUND}

In most clinical situations involving post-traumatic stress disorder (PTSD), cognitive-behavioural therapy (CBT) is the standard treatment. ${ }^{1}{ }^{2}$ However, CBT has several requirements. The therapies that comprise CBT incur costs for time, labour and therapists' expertise, and address the psychological pain of patients remembering traumatic memories. Therefore, it is difficult to adapt CBT as an intervention to many situations, especially those with limited resources, such as postdisaster settings.

Psychological first aid (PFA) is a trusted mentalhealth approach used worldwide to prevent PTSD after a disaster. ${ }^{3-5}$ Although PFA is not a specific therapeutic method for PTSD, it has been endorsed as an early response for persons affected by disasters and major traumatic events. ${ }^{3}$ It is supported mainly because it does not incur large costs or consume the resources of local clinical facilities. The central objective of PFA after a disaster is to provide practical assistance for coping with difficult living situations, such as ensuring physical safety and restoring connections among people. ${ }^{3-5}$ However, little information is available concerning how to provide PFA to survivors of traumatic events after a disaster.
Among the many health-related impacts of the Great East-Japan Earthquake and tsunami, followed by the Fukushima Daiichi nuclear power plant accident on 11 March 2011, radiation exposure was a major public health concern. However, the disasters' effects were not limited to those caused by radiation exposure. Psychiatric disorders, especially PTSD, were prevalent in the disaster-affected areas. ${ }^{67}$ After the disaster, the number of persons suffering from acute stress disorder or PTSD who visited psychiatric outpatient clinics increased in 2011, but returned to predisaster levels in $2012 .^{8}$ As resources were limited, we speculate that many individuals did not consult doctors even if they experienced symptoms. ${ }^{89}$

Soma city is located $40-50 \mathrm{~km}$ north of the collapsed nuclear power plant. It was severely damaged by the nuclear disaster as well as the earthquake and subsequent tsunami. Although many residents lost their houses and family members, some were too old to rebuild their daily lives by themselves. Therefore, Soma's local government built community housing called Idobata Nagaya, which consisted of 5 buildings and 58 private living areas. In addition to providing housing, it was intended to strengthen the emotional ties among the disaster survivors residing in the community. To create a new community among the older residents, lunch was served and residents spent approximately 3 hours together in the dining room daily. Thus, the community residence functioned as a provider of PFA for the disaster survivors.

Here, we report the case of an 80-year-old Japanese woman, who was diagnosed with PTSD after Fukushima's triple disaster. Her recovery was greatly enhanced by the social support she received as a resident of Idobata Nagaya. The details of this case support the effectiveness of Idobata Nagaya as a provider of PFA.

\section{CASE PRESENTATION}

This case concerns an 80-year-old Japanese woman who visited the clinic 5 years after the disaster, suspecting that she had dementia; 'forgetfulness' was her main complaint.

This woman was born in a village near the Pacific-coast fishery. She was married with two children; her husband passed away at a young age, so she worked for manufacturing industry. After retiring from her job, she helped her parents with their 
fishing business and continued to live alone. Her medical history was unremarkable.

In the village where her parents lived, the damage from the tsunami was severe; 14 relatives, including her older brother and sister and her brother's son were lost, but she was able to escape from the tsunami by driving a car by herself. Her two children were alive. More than 50 people died in the village, which originally had 573 residents. She looked for her older sister's body until she found the corpse 40 days after the disaster. Moreover, this woman was asked by the police to view the bodies of more than 10 deceased individuals to confirm their identities.

The woman lived alone in an old house that had collapsed due to the earthquake, so she moved into temporary housing. She moved to Idobata Nagaya after it opened in May 2013. As all the residents had experienced the tsunami, they enthusiastically discussed their traumatic memories and listened intently to the others' stories daily during lunchtime. Parties were hosted there two times a week, a dance class was held once a week and nurses and doctors visited monthly. Even though she did not have any relatives nor old friends in Idobata Nagaya, she was well adapted and very satisfied with her life there.

In the autumn of 2016, a female resident of the community residence began to exhibit symptoms of Alzheimer's-type dementia. She sometimes became delusional and accused other residents of stealing her belongings. Our patient who was also accused and called a thief by this woman was shocked and became very sad and angry because she felt as if she was losing her honourable position as a faithful member in Idobata Nagaya.

Her symptoms of forgetfulness started after this episode. While driving her car, the woman noticed that she was driving in a different direction from her intended destination, and that she had driven through a red light. She became preoccupied with the idea that she might also have dementia. She decided to visit our clinic for her first consult.

\section{INVESTIGATIONS}

Our patient's score on the Post-traumatic Diagnostic Scale (PDS) was 19 points. ${ }^{10}$

\section{DIFFERENTIAL DIAGNOSIS}

Alzheimer's-type dementia.

\section{TREATMENT}

At her first visit to the clinic, no signs of dementia were confirmed. The woman's chief complaint of 'forgetfulness' was judged a dissociative symptom of PTSD. Other PTSD symptoms, such as re-experiencing the traumatic event, avoidance and hyperarousal were noted. ${ }^{1}$

We hypothesised that our patient's PTSD symptoms were more severe when she first moved to Idobata Nagaya, but they improved due to a well-supported life at Idobata Nagaya and her joining in conversations with other survivors there. After our patient became involved in the conflict with the female resident with dementia, she experienced symptoms of relapse and coincidently sought help at our clinic.

We prescribed an selective serotonin reuptake inhibitor (SSRI) (sertraline $25 \mathrm{mg}$ ) as a medical intervention, provided psychological education about PTSD (including its dissociative symptoms), and told our patient she did not have dementia, which contributed to the improvement of her symptoms. ${ }^{111} 12$

We recommended that she take specific psychotherapies for PTSD such as prolonged exposure therapy, but she refused our recommendations with a facial expression of strong fear.

\section{OUTCOME AND FOLLOW-UP}

Subsequently, the woman's symptoms improved dramatically, and there were no more episodes of 'driving without noticing red lights'. She took the SSRI for almost 3 months.

When we visited Idobata Nagaya for a follow-up investigation in the autumn of 2017, the woman's PDS score had decreased by 18 points to $1 .^{10}$

\section{DISCUSSION}

Among the interventions used to prevent the development of PTSD after disasters, PFA is a trusted mental-health approach worldwide; however, little information is available about providing PFA for individuals with PTSD.

We examined the case of a patient who underwent a serious traumatic experience after the Fukushima disasters. Although the patient had been experiencing PTSD symptoms for five and one-half years prior to visiting our clinic, a very good clinical outcome was observed despite the short medical intervention. A possible reason was that the stable environment provided by Idobata Nagaya was conducive to the establishment of warm mutual relationships with other survivors and supporters, and to the prevention of isolation. These factors are essential components of PFA: attempt to provide 'safety and comfort', 'practical assistance' and 'connections with social support'. ${ }^{3-5}$ Moreover, exposure to traumatic memories was spontaneous among the residents, and their discussions about them were considerate and thorough. These discussions might have fostered their habituation to traumatic memories and the processing of cognitive aspects of psychological trauma, which are therapeutic mechanisms of CBT in the treatment of PTSD. ${ }^{13}{ }^{14}$ It is likely that this inadvertent therapy became possible due to the close ties between the residents. The entire community had experienced earthquakes and tsunamis and had lived connected lives. Although the evidence is still evolving, it appears that early interventions that reconnect victims with their families, social support systems and known resources might be most effective in facilitating recovery. ${ }^{3-5} 15$ The approach used by Soma city to develop Idobata Nagaya was congruent with the principles and practices recommended by PFA after a disaster. In contrast, Morita et al reported a case of alcohol use disorder due to social isolation after the nuclear disaster in Fukushima. ${ }^{16}$ Hence, we emphasise the importance of emotional ties among disaster survivors in the improvement of their mental health.

The patient did not have dementia but was experiencing dissociative symptoms, which are common in PTSD. ${ }^{1}$ The patient misinterpreted her dissociative symptoms as signs of dementia, and her anxiety about having dementia motivated her to seek professional consultation. Our present report has shown that such a clinical course is possible in older adults with PTSD. The patient had PTSD symptoms (re-experiencing the traumatic event, avoidance and hyperarousal) for several years, but they were confirmed only through clinical interviews, and were not a motivating factor for seeking consultation. ${ }^{1}$

We made three interventions, namely, giving her an explanation that she did not have dementia, psychoeducation for PTSD and the prescribing of sertraline $25 \mathrm{mg}$. Among these three interventions, we have an impression that her learning that she did not have dementia played the most important part. When she visited our clinic, she had become psychologically dependent on Idobata Nagaya. Therefore, the fear that she might be forced to leave there because of dementia or a bad reputation was enormous. Our explanation likely relieved this fear. Compared with this explanation about not having 
dementia, how psychoeducation on PTSD contributed for her recovery is difficult to evaluate. Because there has been strong ignorance and prejudice related to psychiatric disorders in the rural areas, the concept of PTSD and dissociative symptoms were unfamiliar to her as well as all the other residents. Therefore, the psychoeducation may not have been fully understood. For the 3 months when she was taking the SSRI, she showed recovery. However, it is difficult to estimate precisely how the psychotropic drug contributed, because there are many confounding factors. Furthermore, the period she took the medication was not long enough and she was taking the minimum dosage.

This study has some limitations. The biggest problem is that our case report is lacking any comparisons. This patient might have three other scenarios. The first scenario is that she might have continued to live alone after the disaster and would have recovered from PTSD just with the passage of time. The second scenario is that she could have resided in the community housing but not join in the conversations with others about traumatic memories. Even without the discussions about the earthquake, tsunami and losses, she could possibly recover from the trauma only with the supportive environment at Idobata Nagaya. The third scenario concerns what would happen if she had been receiving any specific CBTs for PTSD.

Our patient did not receive any specific psychotherapies from mental health professionals. We think it is possible that she would show better recovery with CBT for PTSD. The strong fear she showed when explaining to her the exposure techniques indicated that she still maintained some vulnerability to her traumatic memories, which might have led to an overadaptation to, and strong psychological dependence on, the community housing. Her psychiatric symptoms tended to be easily influenced by the atmosphere of Idobata Nagaya and her social position there. Specific CBTs were supposed to improve that tendency.

The questions proposed in the previous two paragraphs were difficult to answer. Therefore, we could just describe them as

\section{Learning points}

- The present case suggests that community housing might contribute to the improved mental health of disaster survivors by providing opportunities to establish mutual trust in other residents. Although community housing cannot be a substitute for post-traumatic stress disorder (PTSD) treatment, such as cognitive-behavioural therapy (CBT), they can provide residents with a strong sense of safety and unity.

- CBT is a standardised approach to PTSD with strong evidence of its effectiveness, but it is difficult to implement in postdisaster settings.

- The patient mistook her dissociative symptoms of PTSD for symptoms of dementia and her misunderstanding motivated her to seek professional help at our clinic. Although she had symptoms of re-experiencing the traumatic event, avoidance and hyperarousal for five and one-half years, they were not a motivating factor in her decision to seek professional consultation. limitations of our study. The rapidity of response, inherent chaos and danger, and limited resources have made it challenging to conduct studies on the effectiveness of various interventions immediately after a disaster. ${ }^{3}$ The accumulation of experiences from individual cases similar to the one described in this report is important for the development of PTSD interventions that are more sophisticated.

Contributors All the authors have approved the manuscript and agree with submission. AH treated the patient and drafted the manuscript, and TM and IY made significant contributions to the manuscript. MT designed the study and revised the manuscript.

Funding The authors have not declared a specific grant for this research from any funding agency in the public, commercial or not-for-profit sectors.

Competing interests None declared.

\section{Patient consent Obtained.}

Provenance and peer review Not commissioned; externally peer reviewed.

Open access This is an open access article distributed in accordance with the Creative Commons Attribution Non Commercial (CC BY-NC 4.0) license, which permits others to distribute, remix, adapt, build upon this work non-commercially, and license their derivative works on different terms, provided the original work is properly cited and the use is non-commercial. See: http://creativecommons.org/ licenses/by-nc/4.0/

(C) BMJ Publishing Group Ltd (unless otherwise stated in the text of the article) 2018. All rights reserved. No commercial use is permitted unless otherwise expressly granted.

\section{REFERENCES}

1 American Psychiatric Association. Diagnostic and statistical manual of mental disorders, fifth edition (DSM-5). Arlington, VA: American Psychiatric Publishing, 2013.

2 Lee DJ, Schnitzlein CW, Wolf JP, et al. Psychotherapy versus pharmacotherapy for posttraumatic stress disorder: systemic review and meta-analyses to determine firstline treatments. Depress Anxiety 2016;33:792-806.

3 Edward MK, Davis RB. Psychological first aid. In: Stoddard FJ, Pandya A, Katz CL, eds. Disaster psychiatry: readiness, evaluation, and treatment. Washington DC: American Psychiatric Publishing, 2012.

4 National Child Traumatic Stress Network/National Center for PTSD. Psychological first aid: field operations guide. (accessed 5 Jan 2018).

5 World Health Organization. Psychological first aid: guide for field workers. Geneva: World Health Organization, 2018. (accessed 5 Jan 2018).

6 Yabe H, Suzuki Y, Mashiko H, et al. Psychological distress after the Great East Japan Earthquake and Fukushima Daiichi Nuclear Power Plant accident: results of a mental health and lifestyle survey through the Fukushima Health Management Survey in FY2011 and FY2012. Fukushima J Med Sci 2014;60:57-67.

7 Tsujiuchi T, Yamaguchi M, Masuda K, et al. High prevalence of post-traumatic stress symptoms in relation to social factors in affected population one year after the Fukushima Nuclear Disaster. PLoS One 2016;11:e0151807.

8 Hori A, Hoshino H, Miura I, et al. Psychiatric outpatients after the 3.11 complex disaster in Fukushima, Japan. Ann Glob Health 2016;82:798-805.

9 Matsumoto K, Sakuma A, Ueda I, et al. Psychological trauma after the Great East Japan Earthquake. Psychiatry Clin Neurosci 2016;70:318-31.

10 Foa EB, Cashman L, Jaycox L, et al. The validation of a self-report measure of posttraumatic stress disorder: the posttraumatic diagnostic scale. Psychol Assess 1997;9:445-51.

11 Hoskins M, Pearce J, Bethell A, et al. Pharmacotherapy for post-traumatic stress disorder: systematic review and meta-analysis. Br J Psychiatry 2015;206:93-100.

12 Cooper J, Carty J, Creamer M. Pharmacotherapy for posttraumatic stress disorder: empirical review and clinical recommendations. Aust N Z J Psychiatry 2005;39:674-82.

13 Foa EB, Kozak MJ. Emotional processing of fear: exposure to corrective information. Psychol Bull 1986;99:20-35.

14 Resick P, Schoicke M. Cognitive processing therapy for rape victims: a treatment manual. Newbury Park, CA: Sage, 1996.

15 Hobfoll SE, Watson P, Bell CC, et al. Five essential elements of immediate and midterm mass trauma intervention: empirical evidence. Psychiatry 2007;70:221-42.

16 Morita T, Tanimoto T, Hori A, et al. Alcohol use disorder due to social isolation after a nuclear disaster in Fukushima. BMJ Case Rep 2015;2015:bcr2015209971. 


\section{Novel treatment (new drug/intervention; established drug/procedure in new situation)}

Copyright 2018 BMJ Publishing Group. All rights reserved. For permission to reuse any of this content visit http://group.bmj.com/group/rights-licensing/permissions.

BMJ Case Report Fellows may re-use this article for personal use and teaching without any further permission.

Become a Fellow of BMJ Case Reports today and you can:

- Submit as many cases as you like

- Enjoy fast sympathetic peer review and rapid publication of accepted articles

Access all the published articles

- Re-use any of the published material for personal use and teaching without further permission

For information on Institutional Fellowships contact consortiasales@bmjgroup.com

Visit casereports.bmj.com for more articles like this and to become a Fellow 